\title{
Teaching and Learning Ojibwe as a Second Language: Considerations for a Sustainable Future
}

\author{
Brian D. McInnes \\ University of Minnesota Duluth/Education, Duluth, Minnesota, United States
}

\begin{abstract}
Successfully revitalizing Indigenous languages is one of the greatest challenges of the present for tribal communities. This is particularly significant when one considers that Native peoples have no other place in the world to retrieve their languages should they disappear. When an Indigenous language is no longer spoken in a community or region, it often ceases to exist as a living language. Teaching and learning language in community-based settings has proven beneficial to increasing awareness and overall proficiency. Instituting Indigenous languages as a medium or topic of study in education systems has been an effective means for many tribes in helping create active centers of teaching and learning. The enhanced systematic use of these languages within community and school-based contexts is necessary to ensuring an integrated and authentic approach to language revitalization. The successful experiences of Indigenous peoples such as the Maori and Native Hawaiians are helpful for tribes such as the Ojibwe who similarly aspire to create a comprehensive and sustainable paradigm of language teaching and learning.
\end{abstract}

Index Terms - Indigenous language revitalization, language immersion education, culture and language, community language programs, language and sovereignty

\section{INTRODUCTION}

The rapid disappearance of tribal languages from daily life has not gone unnoticed in Native communities. A history of systematic linguistic oppression and assimilation efforts has cumulated in the near loss of Indigenous languages in virtually every part of the world. Even in places where the language continues to be spoken with a degree of regularity, older generations of first language speakers are rapidly dwindling. Efforts to revitalize Indigenous languages have been valuable in raising awareness, promoting valuable documentation efforts, and creating emerging networks within which Native language efforts might find long-term continuity (May, 2013).

Communities have attempted to respond to the loss of language in a number of ways. The names of buildings, programs, and street signs are now often composed in the Native language. Language speaking tables and events are increasingly found as regular events on community calendars, and some regions have successfully developed Native language media sources (Noodin, 2013). School-based programs have similarly become widespread and may represent the most common means of teaching and learning Indigenous languages in the present. There is tremendous value in each of these singular initiatives. This paper identifies some strategies that have proven successful in community and school-based settings, and argues that sustainable language use can result from coordinated approaches to teaching and learning across both community and school domains.

\section{INDigenous LANGUAGES: CONTEXT OF REvitALIZATION}

The Indigenous languages of the Americas have a long and rich history. The numerous language types that are inherent to this part of the world encapsulate a unique reservoir of knowledge and perspective (Campbell, 1997). Nichols (1990) cites evidence for some 35,000 years of language use and differentiation. The thousands of languages that were once spoken have now been reduced to hundreds based on the history of colonization (Campbell, 1997; Hinton, 2001). Even in areas where Native languages are no longer spoken, the original sounds of the landscape are preserved in place-names of Indigenous origin. Revitalizing such languages represents an important reclamation of unique local histories and knowledge repositories. Moreover, it represents a repudiation of the circumstances that have resulted in the present linguistic trauma that impacts nearly all Indigenous peoples.

Indigenous peoples themselves are often leading language restoration efforts. Native Hawaiians are perhaps the first Indigenous peoples in the United States to explore and implement comprehensive language revitalization strategies. Inspired by the work of another Indigenous people, the Maori of New Zealand, Native Hawaiians began to make a number of dedicated efforts in the 1980s to use the language in their homes, communities, and programs for young children (May, 2013; Reyhner, 2003). The results of this movement have been exceptional: "Over one thousand people have become fluent Hawaiian-as-second-language speakers. Almost silenced 12 years ago, Hawaiian can now be heard in Honolulu supermarkets as mothers shop with children. While the bulk of the effort in Hawai'i has gone to schooling 
in Hawaiian ... programs are now in place to extend this learning beyond the schools into community-based languagelearning activities." (Henze \& Davis, 1999, p.16)

According to Kamana and Wilson (1996), the early and consistent efforts of community members was critically important in re-establishing the Hawaiian language: "At that time, the Hawaiian medium public school system of Hawai'i had been closed for nearly 90 years and the last generation in which Hawaiian was the common language of all Hawaiians was in their seventies" (p.1). Perhaps the nexus of the community's language revitalization efforts was the institution of a comprehensive P-12 immersion school system. Winning the support and participation of the community was axial to such change, but so too was creating the programmatic and legal infrastructures for such programs to exist (May, 2013). In the case of the native Hawaiian people, it meant changing 100-year-old laws in order to implement their language within school-based programs (McCarty, 2003).

Like the Maori who inspired their efforts, Native Hawaiians have illuminated the way for other Indigenous communities in language revitalization. Not only have they been successful in creating a comprehensive P-12 education system, they have also developed an immersion teacher training program and doctoral programs (May, 2013; Wilson \& Kawai'ae'a, 2007). Efforts to revitalize the Hawaiian language in the community and school systems have had a positive impact on the resurgence of Indigenous identity and establishing Native Hawaiians as leaders in an American context of language revitalization: "Immersion schooling has succeeded in strengthening the Hawaiian mauli, awakening consciousness and self-determination within the Native Hawaiian community, and enhancing children's academic success. In the process, the programme has served as a model and a catalyst for Indigenous language reclamation efforts throughout the USA." (McCarty, 2003, p.154)

Other mainland tribal groups such as the Arapaho, Cherokee, Navajo, and Mohawk have benefited from the pioneering work of the Hawaiians in their respective pursuits of creating comprehensive community-based language revitalization strategies. Dr. Steven Greymorning, one of the founders of the Arapaho language revitalization movement, makes the following observation: "It gave me the opportunity to see the full extent of what was possible by observing firsthand three and four year old children speaking their Hawaiian language. It was like witnessing a miracle, and it was the inspiration of those children that I brought back with me to try to instill within our own language program" (Greymorning, 1999, p.14). There is clear precedent for Indigenous peoples to share inspiration and learn from each other about the benefits of revitalizing traditional languages and cultures (Hornberger, 2008). The experience of forerunners in the Indigenous community has demonstrated that language revitalization is a viable and highly desirable option (May, 2013). Revitalization in contemporary times is not without its challenges. The experience of Ojibwe people from the North American Great Lakes region is revealing of both some key challenges and benefits of restoring traditional culture and language in contemporary times. Like many tribal groups today, the Ojibwe are at a critical point in time whereby restoration of traditional culture and language is possible given a coordinated and careful revitalization strategy.

\section{The OJibwe Language: OJibwemowin}

The Ojibwe language continues to be spoken by several thousand people in the United States and Canada. More fortunate communities have well over 100 speakers while many are left with only a handful or fewer (Gresczyk, 2011). There is a substantial history of documentation, with the first examples of dictionaries and descriptive grammars dating back some 200 years. The development of contemporary language-based materials has become increasingly prevalent over the last couple of decades, and the language is taught in virtually every reservation or urban setting with a significant population of Native peoples. Furthermore, many post-secondary institutions offer Ojibwe as a part of undergraduate or even graduate programmes in both the United States and Canada.

In the over quarter-century that Ojibwe has been taught in school and community settings there are relatively few students who have achieved mastery of the language (Gresczyk, 2011). Even in communities with fluent speakers, naturally occurring instances of spontaneous Native language use is increasingly rare. Intergenerational language transmission in the home, particularly from first language speakers to children, is even more infrequent (Noodin, 2013). While there are many variables that can help account for this trend, including the historic political and continuing social impositions by the dominant society not to use Indigenous languages, stakes remain high. As noted by Fishman (1996), a language can disappear in even a single generation.

Until relatively recent times, the Ojibwe language (Ojibwemowin) was broadly used for a large number of social and practical functions. Hinton (2001) affirms that Indigenous languages have the ability to be descriptive of and responsive to myriad situations and contexts. As a polysynthetic agglutinating language, Ojibwemowin is readily able to synthesize words for new technologies and concepts. Ojibwe, as any living language must, evolves to meet the circumstantial and cultural transitions experienced by the speech community in order to stay alive: "A living language is responsive to its environment. Living languages are in constant use and therefore must be adaptable to changing situations and circumstances" (Benally and Viri, 2005, p.91). The need for modernization notwithstanding, it is critical that an Indigenous language such as Ojibwe retain its original speaking philosophies, functions, and purposes. If care is not taken to preserve the traditional integrity of a language, it risks becoming too much like English and perhaps compromising the special worldview that makes it distinct and valuable (Bonvillain, 2008). 
There is a wide belief in the Ojibwe language teaching and learning community that while the language has the ability to evolve, adapt, and change, it was originally given to Ojibwe people to preserve as a means of sacred communication. Its utilitarian uses notwithstanding, Ojibwemowin continues to be viewed as one of the most valued components of cultural identity by speakers and non-speakers alike (Gresczyk, 2011). Regarded as the key to cultural traditions such as song, narrative, and ceremony, the importance of the language to Ojibwe people cannot be understated; traditional ceremonies and rituals are dependent on the use of traditional language and cannot be performed otherwise (Johnston, 2003). Ceremonial participation thus remains a powerful impetus to learn and use the language on a regular basis. Ojibwemowin is a direct link to some 20,000 years of history, and the essence of the Ojibwe people's identity: "If we -the teachers and students of Ojibwe- sit idly over the next three decades, the language will die. If that is allowed to happen, our children will no longer be Ojibwe. They will be the descendants of Ojibwe people -largely disconnected from the culture of our ancestors and its natural mode of expression- the Ojibwe language" (Treuer, 1996, p.3). Thus it can be understood why there is such a strong imperative to save the language. Not only are age-old ceremonial and cultural practices threatened by the loss of language, so too may be the existence of the Nation itself.

As a language valued for both its everyday and spiritual communicative functions, there are many use conventions that are necessarily observed. Specific genres of stories may be told only during particular times, certain words should never be said out of context, and attention should be given to never offend other human or spiritual beings through careless speech (Johnston, 2003). Special reverence for tribal Elders -who carry a full understanding of how Ojibwe is appropriately spoken - is an integral part of any language revitalization strategy (Noodin, 2013). Like so many Native languages, Ojibwe must be taught with accuracy and respect to ensure that vital meanings are not lost even as new uses are created. These complex meanings make the teaching and learning process a rich and multi-layered protocol that is necessarily rich in cultural knowledge and understanding.

\section{LANGUAGE IN COMMUNITY LIFE}

Attempts to restore the language in community life have taken many forms in contemporary Ojibwe language revitalization (Gresczyk, 2011). A return to traditional place-names in community signage is one such example; not only is this restorative of the cultural history of the community, it also returns the language to everyday use. Environments rich in target language terminology can lead to increased use of the language, of particular importance at the present when so few fluent speakers remain (Hinton, 2003). Place-names have special meaning in that they are often descriptive of origin stories, historical events, local knowledge of flora or fauna, spiritual properties or other features important to the past, present, and future of the community (Johnston, 2003). Language learning always involves more than mastery of lexicon and grammar: equally important is the vital corpus of cultural knowledge, situational relationships, perspective, wisdom, self-knowledge, and truth.

In spite of the declining rates of fluent speakers, general community interest in language remains high amongst many Indigenous Nations (Hornberger, 2008). The broad success in revitalization experienced by Native Hawaiian and Maori peoples has provided continued inspiration for increased language use in the home, workplace, and tribal government centers (May, 2013). Increasingly, Ojibwe communities are declaring Ojibwe as the official language of the tribe- a bold move that clearly establishes the use of Ojibwe as a priority (Gresczyk, 2011). When supported by increased learning opportunities for tribal members such local legislation could have powerful outcomes in making Ojibwe the everyday language of business and social interaction again. This requires a broad commitment of the community to ensure that the language initiative gains enough momentum to have the intended outcome (Hinton, Vera, \& Steele, 2002).

Ensuring the continued vitality of any language requires intergenerational transmission (Fishman, 1996). For many Indigenous languages this often means bringing together tribal members who are two or even three generations apart (McCarty, 2003). Noodin (2013) writes of contemporary trends to renew language within the home, and the transformative power this can have for communities in building greater language use. Whether it is through using only Native language kinship terms, everyday commands and phrases, or comprehensively labeling the home in the target language, there are many things that every family can do to demonstrate their commitment to language revitalization. An effective approach in Indigenous language revitalization is to connect an individual or family with a fluent speaker and create regular Native language speaking times, field trips, and household activities or games together through a master apprentice program (Hinton, Vera, \& Steele, 2002). What seems common amongst such community-based and household strategies is that the efforts must be intentional, sustained, and well planned in order to find long-term success.

Implementing increased community and family-language use strategies were key starting places for Native Hawaiian and Maori peoples (May, 2013). Such initial efforts led to the formation of increased collective initiatives such as the formation of language nests for young children, and eventually the organization and opening of immersion schools (Kamana \& Wilson, 1996). While many of these programs were organized by families committed to the language, the support of local political leadership, education professionals, fluent speakers, and the general community was contributory to the sustainability of the efforts. Noodin (2013) writes how this general pattern of revitalization is happening in Ojibwe communities throughout the Great Lakes region, and that there are at least half a dozen Ojibwe language immersion schools presently open. Revitalizing community language use through the opening and 
maintenance of community-based schools is a powerful way for Indigenous communities to create local centers of language revitalization and maintenance (Gresczyk, 2011).

\section{LANGUAGE LEARNING IN SCHOOL-BASED SETTINGS}

At present there are relatively few domains where Ojibwe is exclusively used as a language of communication. Outside of traditional ceremonies, school-based language programs seem to comprise one of the most consistent forums of regular language use and expression. Ojibwe as a second-language programs are quite prolific but meet with little success in terms of generating fluent speakers (Gresczyk, 2011). Such programs are limited by the small amount of daily classroom time, limited resources, and minimal opportunity for relevant teacher in-service. By contrast, immersion schools seem to be one of the most successful ways of building a functional language community (Noodin, 2013). Immersion work is especially productive in the sense that the primary beneficiaries of such efforts are a generation of children who could sustain the language for several generations themselves. The power of membership in a speech community to effect positive learning has been observed by the Hawaiians (Wilson \& Kawai'ae'a, 2007), Maori (May, 2013), Arapaho (Greymorning, 1999), and Navaho (Benally \& Viri, 2005).

The frequency and duration of in-language contact time in a school-based immersion setting affirms its potential as a means of sustainable language transmission. Authenticity, or relevance to the experience of children learning in a language program, is key to the success of immersion education (Kramsch, 1993). A focus on traditional cultural practices as well as contemporary cultural expressions and knowledge needs is a powerful way of maintaining the interest of children. The immersion classroom is a locale of consistent and focused language usage and constitutes a unique intersection between a student's first and second culture experience. This is particularly important with respect to ever-increasing cultural and ethnic diversity amongst student membership. As noted by Peterson and Coltrane (2003, p.2), "Cultural information should be presented in a nonjudgmental fashion, in a way that does not place value or judgment on distinctions between the students' native culture and the culture explored in the classroom." Culture can be implicitly or explicitly taught in a classroom. Learning does not have to be confined to the classroom as instruction can happen in a variety of contexts (Hinton, Vera \& Steele, 2002). Many Ojibwe language immersion schools regularly spend much of their programming time in the outdoors engaged in traditional life-way practices such as maple syrup making, animal tracking and trapping, and traditional materials collecting.

While not all cultural contexts can be replicated in a school-based setting, there is much that can be taught and learned in such mediums. Children in Ojibwe immersion settings implicitly learn respect for cultural traditions and the target language, and are encouraged to speak Ojibwe beyond the classroom setting (Noodin, 2012). Indeed, Garcia and Shirley (2012) suggest that all such schools, in their efforts to become community sources of language and cultural tradition, be regarded as sacred spaces in and of themselves. Focus on both contemporary subject matter and the interest of students is essential to sustaining linguistic and cultural learning momentum. Benally and Viri (2005) stress the importance of this by describing the deleterious effects when students perceive the target culture as being archaic and non-representative of modern life. Thus the culture of the immersion school must also be rooted in the current experience of students in order to maintain a sense of relevance for them.

A vital quality of perhaps all Indigenous language programs is that they reflect the local culture. This implies not simply cultural products or practices, but also the traditional perspective or worldview of the people themselves. How to not only integrate culture, but indeed, create programs with culture at the core, is essential to creating a language program that is culturally authentic and relevant to the people themselves (Kramsch, 1993). It would be impossible to speak the language without a working knowledge of cultural norms:

Language learners need to be aware, for example, of the culturally appropriate ways to address people, express gratitude, make requests, and agree or disagree with someone. They should know that behaviors and intonation patterns that are appropriate in their own speech community may be perceived differently by members of the target language speech community. They have to understand that, in order for communication to be successful, language use must be associated with other culturally appropriate behavior. (Peterson \& Coltrane, 2003, p.1)

Because of the diversity of traditions in Indigenous communities, cultural goals may also be different from one community or school to the next. This can apply even from one Ojibwe community to the next. Lafayette (2003, p.82) suggests, "Language instructors need to make certain students understand that the traits of the target culture presented in a textbook may or may not be shared by all members of a given cultural group." Cultural goals should therefore represent that which is valued by local peoples, but the goals should also reflect the lived cultural experience of the local community. While there is much that can and needs to be shared amongst communities, respect for local cultural and linguistic expressions is an important consideration.

What is imperative for the ultimate success of both community and school-based language programming is that a connection between each be established. Exposing students to multi-faceted domains of language use is helpful to ensuring the development of linguistic and content-knowledge skills that transcend school environments. Using language in home, ceremonial, sports, government, and social settings is part of community-level restoration. In learning to use culture in the broader community context, students develop a greater sense of the authenticity of the language learning effort (Hinton, Vera \& Steele, 2002). As importantly, students also expand their cultural knowledge of language use, the subtleties and particularities of which might be lost if the language is used only for the teaching of 
school-based content. Operationalizing culture at the core of a program is about restoring the context and motivation for target language use. In creating an environment for learners to engage and participate in culturally-based communication norms and practices, community members are empowered as interested and active learners of the target language and its cultural norms:

Putting culture at the core of language education means preparing students to be culture learners. Thus, it is never enough to find and accept someone else's static definitions of the culture. Words and their meaning are linked to a cultural context, and language and cultural patterns change over time and vary according to the situation. To become effective culture learners, students must develop a variety of learning strategies ranging from reflective observation to active experimentation. (Paige, Jorstad, Siaya, Klein, \& Colby, 2003)

An important unifying community and school activity is the defining of local cultural goals that support language programming. Even general standards, such as the ones related to culture learning in the 1996 Foreign Languages National Standards, can be helpful for emerging programs seeking to define their own specific applications (Lafayette, 2003). Academic and cultural standards are not necessarily mutually exclusive, but their integration requires thoughtful and careful planning.

\section{LANGUAGE PROGRAMS AND CULTURAL Vit ALITY}

Indigenous immersion schools are in a unique position to make a synthesis of traditional knowledge with contemporary ways of learning and knowing. Technology may be gainfully employed in language learning (Paige et al., 2003). At the same time, development of writing systems for previously unwritten languages has generally been a positive act of preservation and continuity (Reyhner, 2003). A hallmark of any language's future sustainability is its ability to be used productively by its speakers (Fishman, 1996). A cumulative challenge of the present is to ensure that the full adaptability of languages like Ojibwe are maximized for the present and future (Hinton, 2001). Schools provide one important source for new linguistic innovations and uses. Not only do new technologies and artifacts need to be named and described, so too do academic and contemporary concepts. The support of the community is necessary such that schools do not singlehandedly bear the burden of advancing the language into the future.

Revitalizing and developing language for myriad aspects of community life ensures that students have the broad opportunity to hear and use language beyond the confines of school programs. Holding recreational programs, cultural events, social activities, business transactions, and government-based communications in Indigenous languages demonstrates their continued relevance and productivity. As suggested by Fishman (1991), a multi-context setting and approach may be the best means of encouraging the survival of Indigenous languages.

Adapting a language for new situations of use requires a deliberate effort to re-discover, borrow, or synthesize terms that encapsulate the essence of an item or concept (Bonvillain, 2008). Finding ways to express traditional values and speaking norms in contemporary institutional structures is imperative for the language's broad use and survival (McCarty, 2003). Like many Indigenous languages, Ojibwe is well designed to describe the myriad relationships that connect people, communities, the land, and spiritual aspects of life (Johnston, 2003). Institutional structures of modernday life present a stark contrast to the egalitarian and distributed nature of traditional modes of existence. Bridging the demands of contemporary and traditional phenomena is a day-to-day reality for the numerous immersion schools that are helping lead the language revitalization path.

Whether through the synthesis of new terms, borrowings from other languages, or some combination therein, the development of new vocabulary and ways of using Ojibwe is an exciting task of the present. A revitalized communication about language between communities is concomitantly necessary to help new terms find common or standardized use. Words for contemporary academic subjects or fixtures provide an important and immediately useable reservoir of terms that can be subsequently used in homes and community settings. Such efforts would also be important to explore in community and home based situations (Hinton, 2001). Finding new terms demands a balance between creativity, language expertise, and mastery of traditional philosophies and contemporary knowledge. It is often far too easy to revert to English-based instruction or dialogue when there are no immediate terms to use in Ojibwemowin. This is a challenge which can and must be overcome in redefining the language as a continuing and useful means of communication.

Finding a balance between academic, linguistic, and cultural objectives is definitional to Indigenous language immersion efforts (Reyhner, 2003). In the half-dozen existing Ojibwe language immersion programs, Elders and first speakers work alongside language learners to create spaces where the Ojibwe language is used to describe all schoolbased routines and activities in a way that is distinctly rooted in Ojibwe culture. The cultural value and perspective of naadamaadiwin [working together cooperatively] is at the heart of how these programs operate. Incorporating cultural artifacts, routines, ceremonial traditions and field trips are contributory to the unique quality of these spaces. While Ojibwe language immersion programs may use many of the same physical and organizational structures as mainstream programs, there is sufficient room for innovation. And although unique from traditional approaches, the way that Ojibwe is taught and learned in school-based contexts can continue to be done in a way that is true to the cultural ways and philosophies of Ojibwe people themselves.

\section{LANGUAGe ExCELLENCE: GROWING STRENGTH TOGETHER}


For many world languages at a critical point in revitalization, establishing quality benchmarks of language use and production is necessary for a sustainable and authentic linguistic future. May (2013) notes the progressive advancements in language excellence achieved by Maori, Native Hawaiian, Navajo, and Cherokee programs, and how such action has strengthened each respective language movement. A significant and common challenge in the continuum of Native language teaching and learning is finding a critical mass of teachers or language mentors (Hornberger, 2008). Excellent language ability is a necessary qualification, as noted by Lightbown and Spada (2013, p.169, "second language learners can only learn the language they are exposed to." It is important that quality language is taught and learned and as that is the model that will be spoken going forward. For teachers who work in school-based programs, knowledge of world language or academic content standards may also be essential requirements. Those educators who work in immersion schools and who have to teach formal academic content through a Native language, require mastery of multiple skill sets (Wilson \& Kawai'ae'a, 2007). Furthermore, while abilities to speak the target language and teach basic academic and classroom skills are important, so too is knowledge of how to teach a language (Hinton, 2003).

In the broad revitalization of Ojibwe, developing quality programs to train teachers and language speakers is a necessity for communities everywhere. Forging partnerships between communities and educational institutions may be one means of ensuring continuous quality language instruction and in-service for community and school-based language revitalization initiatives. In the interim, it is necessary for all community members to become a language teacher, language student, or both. Master speakers, who are increasingly aged in most Ojibwe communities, must also be provided with the requisite support in their efforts to move the language forward. As observed by Hinton, "as speakers age, increasingly, the energy and the burden for language revitalization is among the younger adult generations who are not fluent in their language" (2003, p.79). Both first and second language learners, older and younger alike, have a vital role to play in the broad restoration of Ojibwe culture and language. Demonstrated competence does not necessarily have to be native-like to indicate success (Nieto, 2010). True language revitalization is meant to inspire a lifetime journey of discovery, learning, and use.

\section{A ReVitalized Future}

North American Indigenous language activists and educators work at the critical junction of linguistic sustainability and language extinction. The next quarter century will see the passing of the last natural-born first speakers of innumerable languages. Ojibwe is one of many languages that could become moribund should a sufficient core of speakers not emerge. Oftentimes, the children who are expected to be avid learners are generations removed from language and many facets of traditional culture. Debate over writing systems, the modernization of language, and whether culture and language belong in a school-based setting will continue to rage on in Indigenous education circles. While it does, valuable opportunities to teach children and families slip away every second.

As the Ojibwe language movement gains momentum in communities everywhere, there are several important lessons that have been learned from local and related Indigenous groups. Helping achieve the participation of all members in the language revitalization effort is important to growing broad success in language tables, classes, master-apprentice teams, or immersion programs. Efforts that are inclusive or based on traditional culture will help ensure the integrity of an Indigenous approach, no matter what changes in physical or organizational structures the present demands. It is important for all efforts to promote excellence in language use, and to help develop teacher training models that will ensure continued leadership as elders and master speakers pass on.

Indigenous languages such as Ojibwe will survive into the future propelled by teams of committed activists, and indeed, as aptly termed by Gresczyk (2011), language warriors. There is both room and need for everyone who is sincere and committed to be a part of the effort. Any language effort needs far more than simply teachers and students (Hinton, 2001). Grant writers, legislators, politicians, administrators, curriculum specialists, graphic artists, parents, teaching methods specialists, are just some of the roles. Language revitalization is fundamentally about community, and bringing everyone's contributions and efforts to the forefront.

The present movement to revitalize the Ojibwe language will make or break the unbroken legacy of identity and sovereignty that is necessary for the present and future. Language revitalization requires determination and belief in the transcendence of Indigenous identity through culture and language. The critical synthesis of leadership, faith, and effort shown by the Ojibwemowin teaching and learning community provides the greatest affirmation that the language will survive. For communities who have taken the leap to grow an immersion school, this revitalization will be the most comprehensive and far reaching. An immersion school brings hope to a community and is a place where learning Indigenous identity through culture and language is desirable and important. The long hours, numerous criticisms, and endless planning details are overshadowed by the rewards of seeing and hearing children use and enjoy a language that is their birthright.

Like other dedicated Indigenous language revitalization efforts, Ojibwemowin will continue to evolve as a productive language that is useful in all facets of modern life. It is the teachers of today and tomorrow who will ensure that the Spirit of the language is remembered and extended in this effort to modernize, revitalize, and continue the language for future generations of speakers. Indigenous language immersion education is part of a broader network of language revitalization efforts. Language immersion schools are not meant to stand on their own in the renewal of the language 
and culture for another generation. Other efforts, allies, and community connections are necessary for students to develop and appreciate the richness and diversity of their Native language. Within their classrooms, Indigenous language educators stand on the front lines of creating a future for the language and culture. Every day, these small teams mentor children about honoring the historicity, present, and future of the language and culture. It is time to bring language learning into every aspect of contemporary tribal life. The teaching and learning of Indigenous language is every Indigenous person's inherent vocation, and every non-Indigenous settler's responsibility to support.

The connection between language, culture, identity, and sovereignty is a powerful consideration for Ojibwe and other Indigenous nations. Language revitalization is a fundamental act of asserting tribal sovereignty. Present tribal supported efforts to renew Indigenous languages might consider no longer making language a desirable skill, but indeed, a required qualification for employment or even membership. Such action would unequivocally place Indigenous languages such as Ojibwe in the position of prominence they have long deserved. In the meanwhile, supporting community-efforts to unify and grow language program activities such as immersion schools is necessary. Cherishing the present wisdom of tribal elders and growing language knowledge within the youngest generations are initiatives that will ensure the survival of all Indigenous languages into the future.

\section{REFERENCES}

[1] Benally, A. \& D. Viri. (2005). "Dine Bizaad" (Navajo Language) at a crossroads: Extinction or renewal? Bilingual Research Journal 29.1, 85-108.

[2] Bonvillain, N. (2008). Language, culture, and communication: The meaning of messages (5 ${ }^{\text {th }}$ edn.). Englewood Cliffs, NJ: Prentice Hall.

[3] Campbell, L. (1997). American Indian languages: The historical linguistics of Native America. Oxford: Oxford University Press.

[4] Fishman, J. A. (1991). Reversing language shift: Theory and practice of assistance to threatened languages. Clevedon, England: Multilingual Matters.

[5] Fishman, J. A. (1996). What do you lose when you lose your language? In G. Cantoni (ed.), Stabilizing indigenous languages. Flagstaff, AZ: Northern Arizona University, 80-91.

[6] Garcia, J. \& V. Shirley. (2012). Performing decolonization: Lessons learned from indigenous youth, teachers and leaders' engagement with critical indigenous pedagogy. Journal of Curriculum Theorizing, 28.2.

[7] Gresczyk, R. A. (2011). Language warriors: Leaders in the Ojibwe language revitalization movement. Ed.D Dissertation, University of Minnesota.

[8] Greymorning, S. (1999). Running the gauntlet of an indigenous language program. In J. Reyhner, G. Cantoni, R., N. St. Clair, \& E. P. Yazzie (eds.), Revitalizing indigenous languages. Flagstaff, AZ: Northern Arizona University, 6-16.

[9] Henze, R. \& K. A. Davis (1999). Authenticity and identity: Lessons from indigenous language education. Anthropology \& Education Quarterly 30.1, 3-21.

[10] Hinton, L. (2001). Language Revitalization: An Overview. In K. Hale, and L. Hinton (eds.), The green book of language revitalization in practice. San Diego: Academic Press, 3-18.

[11] Hinton, L. (2003). How to teach when the teacher isn't fluent. In J. Reyner, O. V. Trujillo, R. L. Carrasco, L. Lockard, (eds.), Nurturing native languages. Flagstaff, AZ: Northern Arizona University, 79-92.

[12] Hinton, L., M. Vera \& N. Steele. (2002). How to keep your language alive: A commonsense approach to one-on-one language learning. Berkely, CA: Heydey Books.

[13] Hornberger, N. H. (ed). (2008). Can schools save Indigenous languages? Policy and practice on four continents. New York, NY: Palgrave Macmillan.

[14] Johnston, B. (2003). Ojibway ceremonies. Toronto, ON: McClelland and Stewart.

[15] Kamana, K. \& W. H. Wilson (1996). Hawaiian language programs. In G. Cantoni (ed.), Stabilizing indigenous languages. Flagstaff, AZ: Northern Arizona University, 153-156.

[16] Kramsch, C. (1993). Teaching language along the cultural faultline. In Context and culture in language teaching. Oxford, UK: Oxford University Press, 205-232.

[17] Lafayette, R. C. (2003). Culture in second language learning and teaching: Anthropology revisited. In D. L. Lange \& R. M. Paige (eds.), Culture as the core: Perspectives on culture in second language learning. Greenwich, CT: Information Age Publishing, 161-171.

[18] Lightbrown, P. M., \& N. Spada. (2013). How languages are learned (4 ${ }^{\text {th }}$ edn.). New York, NY: Oxford University Press.

[19] May, S. (2013). Indigenous immersion education: International developments. Journal of Immersion and Content-Based Language 1.1, 34-69.

[20] McCarty, T. L. (2003). Revitalising indigenous languages in homogenizing times. Comparative Education 39.2, 147-163.

[21] Nichols, J. (1990). Linguistic diversity and the first settlement of the new world. Language 66.3, 475-521.

[22] Nieto, S. (2010). Language, culture, and teaching: Critical perspectives ( $2^{\text {nd }}$ edn.). New York, NY: Routledge.

[23] Noodin, M. (2013) Anishinaabemowin: Language, family and community. In L. Hinton (ed.), Bringing our languages homes: Language revitalization for families. Berkeley, CA: Heydey Press.

[24] Paige, M. R., H. Jorstad, L. Siaya, F. Klein \& J. Colby. (2003). Culture learning in language education: A review of the literature. In D. L. Lange \& M. Paige (eds.), Culture as the core: Perspectives on culture in second language learning. Greenwich, CT: Information Age Publishing Inc, 3-17.

[25] Peterson, E., \& B. Coltrane (2003). Culture in second language teaching. Center For Applied Linguistics,

[26] December 2003 (EDO-FL-03-09). http://www.cal.org/resources/Digest/0309peterson.html/ (accessed 3/7/2013).

[27] Reyhner, J. (2003). Native language immersion. In J. Reyhner, O. Trujillo, R. L. Carrasco, \& L. Lockard (eds.), Nurturing native languages. Flagstaff, AZ: Northern Arizona University, 1-6. 
[28] Treuer, A. (1996). Building a Foundation for the Next Generation: A Path for Revival of the Ojibwe Language. Oshkaabewis Native Journal 3.1, 3-7.

[29] Wilson, W. H. \& K. Kawai'ae'a. (2007). I Kumu; I Lala: “Let there be sources; Let there be branches": Teacher Education in the college of Hawaiian language. Journal of American Indian Education 46.3, 37-53.

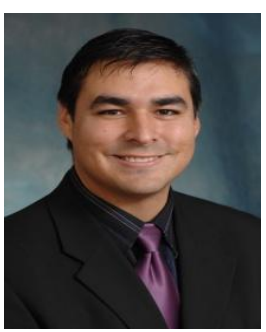

Brian D. McInnes is an Ojibwe from the Wasauksing Reserve in Ontario, Canada. He has Bachelor's degrees from Lakehead and Trent universities, and a Master in Environmental Studies from York University in Toronto, Canada. He holds a Doctorate in Education (teaching and learning) from the University of Minnesota.

He is presently an assistant professor of education at the University of Minnesota Duluth, and the founder of the Enweyang Ojibwe Language Immersion Nest. His teaching and research interests currently include teacher education and licensure, youth leadership development, and early childhood language acquisition and literacy. 